\title{
Sociedade da informação e inteligência em unidades de informação
}

\section{Kira T arapanoff}

D outora em ciência da informação, pesquisadora sênior da Universidade de Brasília e coordenadora do Curso de Especialização em Inteligência Competitiva promovido pelo Instituto Brasileiro de Informação em Ciência e T ecnologia (IBICT) e Instituto N acional de Tecnologia (INT).E-mail: kira@ibict.br

\section{Rogério Henrique de A raújo Júnior}

M estre em ciência da informação pela U niversidade de Brasília e coordenador assistente do Curso de Especialização Inteligência Competitiva promovido pelo Instituto Brasileiro de Informação em Ciência e Tecnologia (IBICT) e Instituto N acional de Tecnologia (INT). E-mail: rogerio@ ibict.br

\section{Patricia M arie Jeanne Cormier}

Bibliotecária da Caixa Econômica Federal e especialista em inteligência competitiva pelo Instituto Brasileiro de Informação em Ciência e T ecnologia (IBICT) e Instituto N acional de T ecnologia (INT). E-mail: cormier@ caixa.gov.br

\section{Resumo}

Aborda o conceito de inteligência competitiva aplicada a unidades de informação. Discute a atuação da unidade de informação no contexto da sociedade da informação, propondo a abordagem da inteligência competitiva para o monitoramento ambiental de informações e adequação organizacional ao contexto. Sugere a estruturação de um sistema de inteligência com utilização de ferramentas de tratamento e agregação de valor à informação apropriadas. Cita exemplo de utilização de sistema de inteligência competitiva em unidade de informação, que pode ser replicado, ou usado como exemplo, por outras unidades de informação.

\section{Palavras-chave}

Sociedade da informação; Inteligência competitiva; Sistema de inteligência competitiva; Monitoramento de informações; Data minig; Data warehousing; Redes neurais.

\section{Information society and the use of intelligence in information units}

\begin{abstract}
The approach and concept of competitive intelligence is applied to information units. It is discussed the role of information units in the Information Society. The competitive intelligence approach is proposed for the organization's monitoring for information for its better positioning in the environment and market. The structing of an intelligence system is suggested as well as the use of appropriate tools to add value to the information. An example is cited for the competitive intelligence use in information systems that can be replicated, or adopted as a model, by other information units.
\end{abstract}

\section{Keywords}

Information society; Competitive intelligence; Information monitoring; Competitive Intelligence system; Data mining; Data warehousing; Neural networks.

\section{INTRODUÇÃ O}

A o pensarmos em inteligência, remetemos-nos imediatamente à capacidade das organizações ( entre elas as unidades de informação) de monitorar informações ambientais para responder satisfatoriamente aos desafios e oportunidades que se apresentam continuamente. Podese dizer que a inteligência visa, principalmente, a imprimir um comportamento adaptativo à organização, permitindo que estas mudem e adaptem os seus objetivos, produtose serviços, em resposta a novas demandas do mercado e a mudanças no ambiente.

Possuir inteligência organizacional ${ }^{1}$ está associado à busca sistemática, efetiva eproativa de posturas ligadas à estratégia, à relação organização e ambiência externa. 0 processo de geração de inteligência nas organizações, a partir do prisma da informação (figura 1).

\section{FIGURA 1}

\section{Etapas na geração de conhecimento e inteligência}

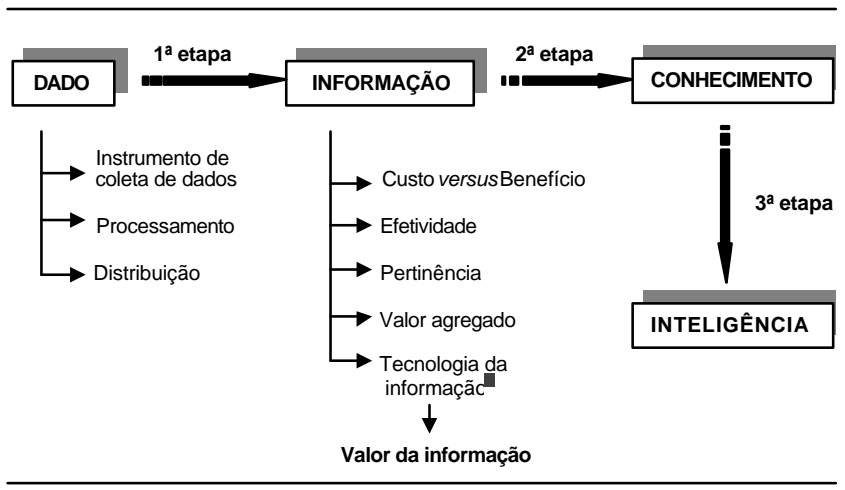

(Fonte: baseado em T jaden, 1996)

${ }^{1}$ A informação dispersa não constitui inteligência. A partir da estruturação da informação é que a inteligência passa a existir. W eick apud Nonaka \& Takeuchi, 1997 (p. 635) desenvolveu a teoria da inteligibilidade, segundo a qual a realidade é uma realização contínua que surge dos esforços de criar a ordem e tentar entender o que ocorre. A inteligibilidade enfatiza que as pessoas tentam tornar as coisas racionalmente responsáveis para si mesmas e para os outros, ou seja, a premissa básica para se fazer inteligência é agregar valor à informação, é estruturá-la de modo que a mesma passe a ter um valor, uma importância contextual da organização.

${ }^{2}$ Emprego do conhecimento científico para especificação de como fazer as coisas no domínio do conjunto convergente da microeletrônica, computação (software e hardware), telecomunicações/radiodifusão, optoeletrônica e engenharia genética (Castells, 1999). 


\section{Kira T arapanoff / Rogério H enrique de A raújo Júnior / Patricia M arie Jeanne Cormier}

A geração do conhecimento vai estar apoiada em dois aspectos interligados:

- valor da informação;

- validade da informação para o processo decisório.

A mudança mais significativa que ocorre na ambiência é o que se convencionou chamar, entre outras denominações, de sociedade pós-industrial. Esta diz respeito essencialmente às mudanças na estrutura social, às transformações que se produzem na vida econômica e na estrutura profissional e, por fim, às relações que se estabelecem entre a teoria ea prática experimental, entre ciência e tecnologia.

0 modus operandi da sociedade pós-industrial identificase com o da sociedade da informação. T rata-se deum modo de desenvolvimento social eeconômico em quea aquisição, armazenamento, processamento, valorização, transmissão, distribuição e disseminação da informação conducente à criação de conhecimentos e à satisfação das necessidades dos cidadãos e das organizações desempenham um papel central na atividade econômica, na criação de riqueza, na definição da qualidade de vida dos cidadãos e das suas práticas culturais ( Livro V erdepara a Sociedadeda Informação em Portugal: http://www.missao-si.mct.pt/livroverdel Ivfinal.zip)

\section{O NOVO AMBIENTE DAS UNIDADES DE IN FO R MAÇÃO}

\section{C aracterização das unidades de informação}

A s unidades de informação ${ }^{3}$ (bibliotecas, centros e sistemas de informação e de documentação) foram e são, tradicional mente, organizações sociais sem fins lucrativos, cuja característica como unidade de negócio é a prestação de serviços, para os indivíduos e a sociedade, de forma tangível (produtos impressos), ou intangível (prestação de serviços personalizados, pessoais, e hoje, cada vez mais, de forma virtual - em linha, pela Internet).

No entanto, em especial nas duas últimas décadas, as unidades de informação têm sofrido redução orçamentária, tanto no Brasil como no exterior, e têm sido submetidas à competição por recursos/insumos de toda espécie, em especial por recursos financeiros (Y oung, 1994, p. 110). A pergunta que as unidades informacionais têm se feito é: 0 que fazer quando as fontes tradicionais de fomento

\footnotetext{
${ }^{3}$ Unidade de Informação - instituições voltadas para a aquisição, processamento, armazenamento e disseminação de informações (IBICT, 1989, p.i)
}

diminuem os seus repasses? Formas cooperativas para a maximização de recursos são estudadas, mas também aflora a possibilidade de cobrança da prestação diferenciada de serviçose produtos internacionais. $E$, neste caso, devese cobrar por serviços informacionais? Como cobrar, quando cobrar, quanto cobrar?

A ssuntos complexos como livre acesso à informação, barreiras para o livre acesso à informação pública e cobrança direta por serviços bibliotecários com valor agregado têm provocado discussão e debate entre os profissionais da informação. 0 posicionamento tradicional é que os serviços bibliotecários são um bem público (domínio público) e que o acesso livre à informação é um direito fundamental de cada cidadão em uma sociedade democrática. Este posicionamento reflete uma visível preocupação com a finalidadee a justiça social.

A questão principal em debate é o foco na definição do que é bem público, em instituições de serviço (público). A importante distinção entre informação como bem público e informação como bem econômico (commodity) está na diferença entre a informação a serviço da eqüidade social e aquela que oferece um portfólio ${ }^{4}$ de serviços, representando vários graus de eficiência, a preço compatível de mercado competitivo.

A queles que vêem a informação como um bem público enfatizam unicamente a natureza econômica da informação. A informação tem característicaseconômicas atípicas que a distinguem de ativos (commodities) mais tangíveis. A informação pode se expandir, ser completada, é capaz de ser substituída, transportável, difusa e pode ser compartilhada. Como um produto/mercadoria, a informação não se deprecia e é disponível livremente, tem um valor que cresce com a reutilização e a sua apresentação sob outra forma (reembalagem) e é extremamente difícil de controlar. D esta forma, 0 argumento do bem público afirma que 0 acesso amplo à informação resulta em um uso crescente que beneficia a sociedade como um todo, e não apenas partes desta sociedade (Y oung, 1994, p. 108).

\footnotetext{
${ }^{4}$ Portfólio - seus componentes são os negócios e produtos que constituem a empresa (K otler \& A rmstrong, 1993).
} 
A rgumenta-se também que a crença de que toda a informação estará disponível para todos na Internet, em qualquer lugar, a qualquer momento, é baseada em um pressuposto equivocado a respeito da natureza humana. $\mathrm{N}$ ada é inteiramentelivre, e problemas de direitos autorais devem ser resolvidos, nos seus aspectos do que pode ser digitalizado (o que é ou não de domínio público) e quem pode ter acesso a esses materiais ${ }^{5}$. 0 problema de compatibilizar interesses conflitantes de propriedade intelectual com o acesso livre e igual impõe restrições sobre a consulta de materiais produzidos.

A biblioteca nos moldes tradicionais é a única que pode disponibilizar livremente os materiais com direitos de autor reservados. A biblioteca tradicional seria assim 0 único lugar onde os leitores podem consultar livremente não somente os materiais com direitos autorais reservados, mas também bases de dados (com acesso licenciado) que não podem ser utilizadas de qualquer lugar, por qualquer pessoa no espaço virtual. Enquanto a questão dos direitos autorais do ciberespaço não estiver resolvida, será a biblioteca tradicional o lugar onde qualquer cidadão poderá ter livre acesso a qualquer obra com direitos autorais reservados, sem pagar por esses direitos ( $M$ ann, 1999).

A escassez de recursosé uma das vertentes que tem mudado a postura das unidades informacionais em termos administrativos, organizacionais e como unidades de negócio que vêem, hoje, a informação oferecida como um bem econômico, que pode ser vendida em forma física ou na forma de comércio el etrônico, e não mais apenas como um benefício cultural ou social, suprindo lacunas para 0 crescimento individual dos cidadãos, que, acredita-se, 0 mercado por si só nunca supriria de forma adequada.

A sorganizações sem finslucrativostêm procurado formas adicionais de suprimento de fundos, comportando-se mais como organizações com fins lucrativos do que sem fins lucrativos (DEES, 1998, p. 56).

\footnotetext{
${ }^{5}$ A lém do livre acesso, outro ponto evidente é a restrição quanto à utilização da informação cujos limites são impostos pela legislação que regulamenta 0 direito autoral. Com relação à utilização da informação veiculada na Internet, por exemplo, a nova Lei do Direito A utoral pontua que os direitos autorais continuam a ter sua vigência no mundo on-line da mesma maneira que no mundo físico. A transformação das obras intelectuais para bits em nada altera os direitos das obras originalmente fixadas em suportes físicos, como já referido anteriormente. 0 direito de reproduzir uma obra é exclusivo de seu titular, inclusive o direito de reproduzi-la eletronicamente em uns e zeros (para serem lidos por computador). E se alguém armazena de forma permanente, no seu computador, material protegido pelo direito autoral, uma nova cópia é feita, necessitando a mesma, portanto, de uma autorização expressa do respectivo titular (Gandelman, 1997, p. 154-155).
}

A outra grande vertente, como já visto anteriormente, tem sua origem na mudança paradigmática da sociedade, que inicia um novo ciclo produtivo, centrado na informação e no conhecimento e que tem a informação como um bem econômico: a Sociedade da informação. N esta, o bem-estar econômico das nações depende, cada vez mais, de sua habilidade em acessar e explorar os acervos de conhecimentos tanto internos como externos. Conhecida também como era digital, esta sociedade está estreitamente ligada à qualidade da infra-estrutura de telecomunicações do país.

\section{Como atribuir valor à informação}

A gregar valor a produtos e serviçossignifica imprimir aos mesmos uma diferenciação que os torna mais atraentes aos olhos dos consumidores, quer seja em termos de qualidade, rapidez, durabilidade, assistência ou preço. Podem ser identificadas seis categorias de atividades de valor agregado : facilidade de uso, redução de informação desnecessária, qualidade, adaptabilidade ${ }^{6}$, economia de tempo e economia de custo (T aylor, 1986).

N o que se refere à informação, a agregação de valor excede os métodos tradicionais de consulta, pesquisa e disponibilização de informação aos usuários das também tradicionais bibliotecas. A s atividades do bibliotecário podem incluir: treinamento, trabalho especializado e atendimento a consultas dos usuários sobre seleção de fontes de informação; desenvolvimento de estratégias de pesquisa/busca; avaliação da informação.

Ele pode participar do planejamento e das atividades decisórias da organização, onde exerce o processamento, reunião e coleta de informações ambientais pertinentes à organização (vigilância informacional), procurando desenvolver um entendimento íntimo de como a informação é usada. D eve buscar entender qual o impacto da informação adquirida no desenvolvimento do indivíduo e da organização, além de procurar saber como os conhecimentos de cada um podem beneficiar a todose a organização (CH O O , 1998, p.215; Q uinn; A nderson \& Filkenstein,1996).

${ }^{6}$ Refere-se à habilidade de o serviço oferecido ser compatível com as necessidades do usuário em seu ambiente de trabalho. 
Considerando que as unidades de informação venham a estabelecer um custo para seus serviços e produtos, propomos, baseados em K otler (1998), uma metodologia para a atribuição de valor à informação. Segundo ele, há alguns itensque contribuem para a determinação do valor a ser cobrado por um serviço, são el estempo, energia física e energia psíquica. D essa maneira, tomemoso processo de pesquisa bibliográfica e as atividades que este serviço abrange até a entrega do produto final ao consumidor: a informação. A variável tempo será determinada pelo próprio demandante do serviço, pois a urgência para a utilização da informação irá variar conforme as necessidades de cada um. A s variáveis custo de energia física e energia psíquica estão diretamente relacionadas com o tipo de profissional que está envolvido na elaboração da pesquisa. A s demais variáveis são dependentes dos múltiplos contextos onde está sendo oferecido o serviço de pesquisa.

\section{A plicação da inteligência competitiva em unidades de informação}

$\mathrm{N}$ a busca da informação, a organização deve observar seletivamente a grande quantidade de sinais criados em um ambiente dinâmico, interpretar as mensagens confusas e perceber os indícios relativos às suas atividades $e$ objetivos (Choo, 1998). Porter (1996) desenvolveu um modelo centrado na rivalidade existente entre empresas similares. A s cinco forças competitivas identificadas determinariam a rentabilidade das mesmas e influenciariam os preços, os custos, o investimento necessário das empresas e os elementos do retorno sobre 0 investimento (figura 2).

Com relação às unidades de informação, é condição precípua a identificação do seu macroambiente para que se possa determinar, a partir daí, a possibilidade de utilização da inteligência competitiva em seus processos. Tarapanoff (1998) identifica algumas forças externas condicionantes do desempenho das unidades informacionais: a explosão da informação, a tecnologia da informação, novas demandas dos usuários, propriedade intelectual, redes, competição com a indústria de conteúdosprivada, escassez de recursos, desenvolvimentos legais, cooperação (inclusive as novas formas cooperativas de consórcio). Sugere-se que os conhecimentos que a organização e os seus funcionários têm sobre 0 desenvolvimento da própria área de ciência da informação e das suas disciplinas complementares também afetam 0 desempenho dessas unidades.
FIGURA 2

As cinco forças competitivas que determinam a rentabilidade da empresa

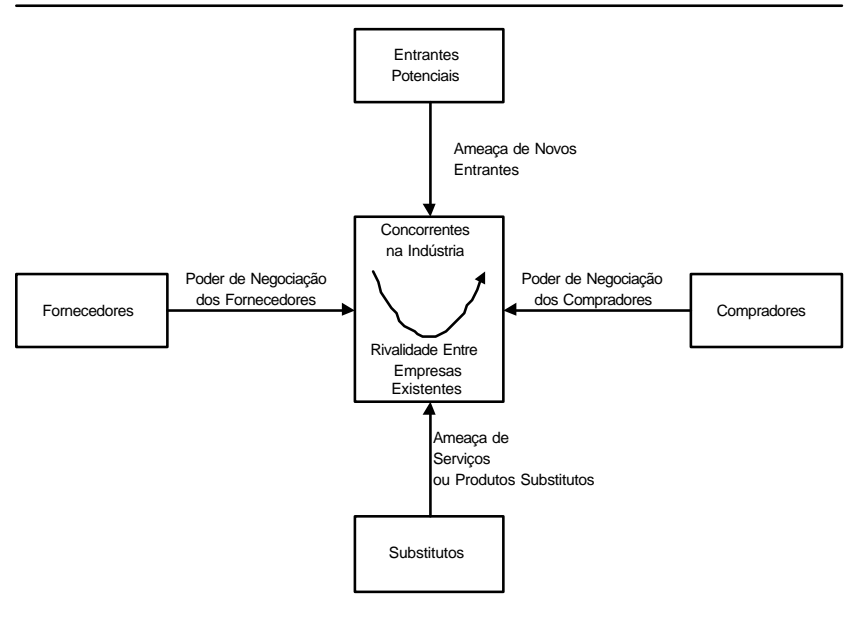

(Fonte: Porter, 1996)

Em unidades de informação, a postura competitiva associa-se à pró-atividade no atendimento às demandas dos usuários, ou seja, está intimamente relacionada à melhor oferta de produtos e serviços, à antecipação às novas tendências em relação à novas estruturas, à facilidade de acesso à informação, à formação, à agregação de valor e qualidade a esses produtos, bem como à sua personalização (customização), função de redes e de posicionamento no mercado de acordo com as demandas específicas.

A plicando o modelo de Porter (1996) às unidades de informação e tomando como base as premissas acima, podemos sugerir que os elementosque podem condicionar o retorno do investimento nessas organizações são os seguintes:

1. A meaça de novos competidores - Indústria privada;

2. A meaça de produtos substitutos - Internet;

3. Poder do fornecedor - Redes e consórcios;

4. Poder de barganha do cliente - Compra de serviços alternativos;

5. Rivalidade dos concorrentes - Pró-atividade.

A s unidades de informação devem explorar o fato de a cooperação permear vários de seus processos, principalmente no que diz respeito à aquisição da informação (poder do fornecedor). É importante a implementação de uma rede de comunicação entre diversas bibliotecas, cujo objetivo é estabelecer uma teia de informações capaz de localizar com rapideze com baixos 


\section{Sociedade da informação e inteligência em unidades de informação}

custos fontes produtoras e levar ao cliente/usuário o produto informacional com valor agregado. A s fontes de informação podem ser convencionais ou não convencionais, sendo que, no segundo caso, há a necessidade da val idação de informações por especial istas, que pode ser também um produto a ser oferecido pelas bibliotecas como forma de enfrentar a concorrência.

Segundo Gilad apud Sapiro (1993), quando a inteligência competitiva se insere no tecido organizacional, os benefícios podem ser facilmente apontados, como:

1. identificação de novas oportunidades de negócios;

2. ideais compartilhados;

3. crescente habilidade para antecipação de surpresas;

4. aumento das habilidades gerenciais;

5. integração de vários pontos de vista.

No caso das unidades de informação, a inteligência competitiva se relaciona à:

- identificação de necessidades de usuários, quando é necessário um bom conhecimento do mercado de atuação para focar nichos de usuários potenciais, usuários virtuais, usuários esporádicos e outros;

- postura pró-ativa (desenvolvimento de coleções de acordo com interesses específicos, parcerias com instituições que oferecem produtos afins);

- estabelecimento de redes de informação, dasquaisfaçam parte especialistas cuja função éa validação da informação.

Essesitens se relacionam entre si de modo a estabelecerem um processo detran sformação de dados em conhecimento, que tem início com a identificação de necessidades de informação, bem como do tipo de informação necessária: informação para o negócio, informação para a pesquisa e desenvolvimento, informação para a produção e outras. A ssim, "Inteligência Estratégica" enfatiza a busca de informações para a tomada de decisão e para 0 planejamento estratégico; "Inteligência para N egócios" é o monitoramento de informação sobre negócios e mercados; "Inteligência Competitiva" foca informações sobre produtos e serviços oferecidos por empresas similares; "Inteligência T ecnológica" enfoca informações de ordem tecnológica e social. A lia-se a isto uma boa dose de antecipação e de prospecção para a adoção de novos modelos de produtividade. 0 u seja, a inteligência competitiva deve ser empregada como instrumento para que a unidade de informação seja capaz de analisar e estabelecer novos paradigmas de foco informacional, não só para o seu ambiente externo, onde estão seus concorrentes e clientes/usuários externos, como também para o seu ambiente interno.

\section{Sistema de Inteligência}

A adoção e a manutenção de um Sistema de Inteligência em U nidade de Informação é assegurada por uma série de procedimentos que necessitam estar sempre em revisão, dada a constante mutação e flexibilidade de qualquer mercado, seja de informação, seja de bens ou serviços. A lguns destes procedimentos são:

- posicionar o Sistema de Inteligência de acordo com o tipo de informação requerida (produção, pesquisa, desenvolvimento, negócio);

- definir custos de operações;

- monitorar informações formais e informais;

- estabelecer redes de especialistas que garantam o seu funcionamento;

- posicionar os profissionaisda informação de acordo com a demanda, quando as atividades de cada um devem estar bem clarase descritas, com especificações e normatizações dos serviços oferecidos;

- estabelecer um eficaz canal de comunicação entre os bibliotecários e os usuários;

- validar as informações coletadas;

- elencar, para cada fator crítico de sucesso ${ }^{7}$ indicado pelo usuário que necessita da informação, as fontes que deverão ser utilizadas;

- criar um sistema de apoio de busca de informação que possa ser customizado e que faça estudos de produção de informação e de fontes mais consultadas;

- criar um sistema de segurança de informação.

${ }^{7} \mathrm{~N}$ úmero limitado de áreas nas quais os resultados, se forem satisfatórios, irão assegurar um desempenho competitivo de sucesso para a organização. Os FCS são os meios que garantem a realização dos objetivos da organização. 
O sprocessos da unidade de informação podem se adequar ao Sistema de Inteligência, já que auxiliam no monitoramento de dados, indicam tendências de pesquisas e mantêm relacionamento com especialista, como, por exemplo:

\section{A tendimento a usuários}

O bibliotecário de referência, responsável pela "negociação" com os clientes/usuários, perceberá as tendências de pesquisas, repassando informações importantes para o desenvolvimento de coleções que consubstanciam o acervo da biblioteca, bem como na modelagem e montagem de um sistema de atendimento pró-ativo ao usuário/cliente.

\section{Estudo de usuários}

Permitirão a prospeção e a antecipação das necessidades dos usuários, o que irá garantir a vantagem competitiva das unidades de informação em relação a seus concorrentes. $\mathrm{N}$ ão servirá apenas para a geração de indicadores quanto ao perfil do cliente/usuário, mas também deverá gerar indicadores para a formulação de itens de controle de qualidade dos serviços prestados pelas unidades de informação.

\section{Estudos bibliométricos e infométricos}

Estes estudos representam a base de sistemas automáticos de análise de informação. A través de cálculos, informam quantas vezes palavras são utilizadas, apontando para tendências em áreas consagradas, que constam de bases de dados. T ais estudos podem ser feitos por bibliotecas.

Serviços de D isseminação Seletiva da Informação - DSI

A pós o percurso de toda a cadeia de valores da informação, a biblioteca fornecerá ao seu cliente/usuário o produto informacional que atenda a suas necessidades específicas de acordo com o seu perfil de interesse, quer seja para estudo, para pesquisa ou para a tomada de decisão.

\section{ALGUMASTÉCNICAS PARA O TRATAMENTO DAS INFORMAÇÕES}

\section{Redes N eurais}

Para se ter acesso à boa informação sempre foi prioritário 0 desenvolvimento de instrumentos que permitissem a implementação da "lei do menor esforço", capacitando a extração de informações realmente relevantes em um contexto de produção exponencial de dados. A construção de redes neurais, por exemplo, é a tentativa de utilizar a tecnologia da informação aproximando-a ao método humano de processamento de dados, por meio de associações e capacidade de aprender. D esta forma, uma rede neural compreende um conjunto de nós interligados chamados de neurônios. Cada neurônio conecta-se e envia informação para os demais da camada seguinte, de acordo com pesose conexões predefinidos. A s redes neurais têm capacidade de tratar dados incompletose distorcidos, produzindo resultados satisfatórios a partir de generalizações (A Imeida \& D umontier, 1996).

\section{Data W arehousing}

A tecnologia de $D$ ata $W$ arehousing surge com a mesma proposta de otimização do uso da informação, a fim de transformá-la em diferencial competitivo. D esponta como uma das principais arquiteturas deste final de século. Foi desenvolvida com a finalidade de prover suporte à tomada de decisão, tendo como elementos básicos: orientação para o objeto, integração, tempo como variável e a nãovolatilidade de dados.

\section{Como funciona o Data W arehousing?}

De modo geral, o funcionamento do DW é simples de entender. U ma das premissas do sistema é a integração de dados. Dados de várias fontes são coletados e migrados para 0 ambiente do $D$ ata $W$ arehousing, onde recebem um tratamento visando à sua padronização, que facilitará a recuperação de informações (os dados já sofreram interferência, já possuem valor agregado, então são considerados informação) pelo usuário final.

Em informativo técnico editado na Internet, a Revista U nicamp explica as etapas para a implementação de um Data $W$ arehousing:

- construir um modelo lógico das informações disponíveis nas aplicações fontes; 
- trabalhar com os gerentes e analistas de negócio para determinar qual o conjunto de informações que deve ser levado para o $D$ ata $W$ arehousing - este conjunto é o que será utilizado para a tomada de decisões;

- construir um modelo de transição que identifique dimensões e fatos;

- obter, dos analistas de negócios que fornecem informações aos gerentes, o nível de agregação que deve ser utilizado, a freqüência e periodicidade de carga dos dados no Data W arehousing;

- construir o projeto-piloto e determinar a sua aderência aos requisitos exigidos.

Dados de diversas fontes bibliográficas podem ser os al imentadores de um sistema $\mathrm{D}$ ata $\mathrm{W}$ arehousing para que, após a padronização oferecida pelo sistema, possam ser disponibilizadas ao cliente final, sob a forma de informação, possibilitando a identificação de tendências de pesquisas ou autores que mais produzem em um determinado assunto. Esta aplicação diz respeito a um serviço tradicional de bibliotecas, isto é, pesquisa em base de dados, que, a partir da tecnologia de $D$ ata $W$ arehousing, seriam integradas. $\mathrm{N}$ a verdade, esta tecnologia poderia ser um instrumento para a aplicação da técnica bibliométrica, que é o estudo de aspectos quantitativos da produção, distribuição e uso da informação registrada. Desenvolve modelos matemáticos e medidas para esses processos e depois os utiliza para a previsão e tomada de decisão (T arapanoff, 1995).

\section{D ata M ining}

Estudos para o desenvolvimento de meios e métodos que permitam a eficaz gestão do conhecimento constituem uma ten dência no atual mundo competitivo e gl obalizado. $\mathrm{N} o$ entanto, o diferencial competitivo é justamente a aplicação da tecnologia certa para cada tipo de demanda, ou seja, o profissional envolvido no processo de transformação de inteligência em conhecimento ainda representa um importante fator crítico de sucesso para que a adequada tecnologia seja empregada, o que representará um correto investimento de tempo, recursos materiais e financeiros.

Davenport \& Prusak (1998) ilustram, na figura 3, a necessidade de especialização do gestor da informação.
FIGURA 3

\section{D iagrama da gestão do conhecimento individual}

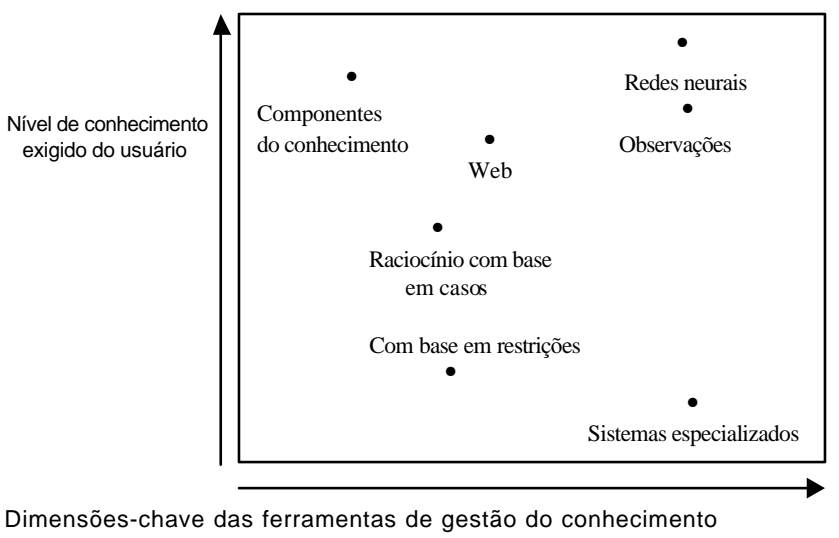

(Fonte: Davenport \& Prusak, 1998)

\section{Conclusões sobre a aplicação de redes neurais, DW e DM em unidades de informação}

É mais fácil visualizar a aplicação de tecnologias em organizações com finslucrativos. A vantagem competitiva sempre é associada a ganhos, a lucros, a incorporações e fusões no mercado, ou seja, ao mais restrito sentido da palavra competição. Em organizações como bibliotecas que existem sem o objetivo precípuo de lucrar, a utilização de R edes $N$ eurais, de D ata W arehousing ou de D ata M ining parece ser uma realidade bem distante, apesar deterem como matéria-prima os mesmos insumos que as bibliotecas, ou seja, os dados, a informação e o conhecimento. Falta, a essas organizações, uma estrutura administrativa bem definida, como empresas comerciaisa tem. A adoção dessas estruturas não significa, no entanto, mudanças na missão ou nos objetivos das unidades de informação.

\section{A INFORMAÇÃO TRATADA}

A informação resultante da aplicação de tecnologias é a informação que alimentará o sistema de Inteligência de U nidades de Informação. A raújo Jr. (1998) identifica os tipos de informação que integram tais sistemas:

1- Informação para a organização - definida como a informação voltada para a gestão (informação administrativa), para melhorar processose produtos, além da manutenção da organização. Estas informações reorientam e subsidiam decisões sobre a atuação e manutenção do negócio de uma empresa: são, por isso, imprescindíveis à sobrevivência e ao aprimoramento empresarial; 
2- Informação para o cliente - informação voltada para o perfil de interesse do cliente/usuário da organização e em consonância com a proposta e capacidade da empresa. Este tipo de informação deve ser utilizada para viabilizar a prestação de serviços.

3- Informação tecnológica - todo o conhecimento de natureza teórica, econômica e mercadológica gerencial, social etc. que, por sua aplicação, favoreça o progresso de aperfeiçoamento e inovação.

Baseado nisso, o quadro 1 reúne, conforme o tipo de informação proposta, as ferramentas adequadas para a geração de vantagem competitiva em unidades de informação.

A s questões que antecedem a disponibilização dessas informações são bem conhecidas do profissional atuante nas unidades de informação: que tipo de informação para a organização, para o cliente, tecnológica- é necessária para 0 atendimento satisfatório do usuário final? 0 nde encontrá-las, ou em que fontes? A partir das respostas e da identificação desses insumos, já estão prontos os dados que seriam transportados para um ambiente $D$ ata W arehousing previamente instalado na unidade de informação, para que fossem codificados e uniformizados, quando, então, seriam disponibilizados ao usuário com valor agregado.

N o que se refere à informação, a agregação de valor excede os métodos tradicionais de consulta, pesquisa e disponibilização de informação. 0 acesso virtual a todo tipo de informação permite ao bibliotecário ter como aliados requisitos como rapidez e precisão, e, como há ênfase no compartilhamento e em parcerias, várias fontes podem ser consultadas, oferecendo a possibilidade de escolha ao cliente. $\mathrm{H}$ á de se considerar, também, as necessidades específicas de cada usuário. D esta maneira, a demanda de cada cliente deve ser analisada, ou seja, o que se pede - dado, informação ou informação analisada? Tal fato está relacionado ao preço que se irá cobrar pelo produto final que será repassado ao cliente (quando for o caso).

É bom ressaltar a visão de (Barter Jr., 1994), para quem, a despeito de toda a revolução tecnológica e de instrumentos cada vez mais avançados para o controlee disponibilização de informações, o importante é o investimento no pessoal qualificado para 0 atendimento dos clientes. Para ele, a capacidade para a inovação é proporcional ao grau de delegação "empowerment" dada a os empregados da unidade de informação. 0 autor ainda aponta algumas das condições necessárias para que a biblioteca acompanhe a evolução do mercado em que atua:
QUADRO 1

\section{Informação e vantagem competitiva em unidades de informação}

$\begin{array}{ll}\text { TIPOLOGIA DA } & \text { VANTAGEM COMPETITIVA } \\ \text { INFORMAÇÃO } & \text { PARA ASUNIDADESDEIN - } \\ & \text { FORMAÇÃO }\end{array}$

1- Informação para a

A plicação das tecnologias da infororganização mação e controle de qualidade.

2- Informação para 0 cliente

Custo, pró-atividade, personalização, agregação de valor e acessibilidade.

3- Informação tecnológica Compartilhamento de conhecimento.

(Fonte: baseado em A raújo Jr., 1998)

- colocar os clientes ( não tratá-los como usuários ou como quem empresta livros) como foco central da missão da biblioteca;

- adaptar todos os serviços oferecidos para atender às necessidades dos clientes, sempre se utilizando de caminhos cada vez melhores para servi-los;

- incentivar ostaff dasunidades de informação, lembrando que a tecnologia é somente um instrumento para o processo da validação da informação, o importante é que as pessoas saibam se utilizar dos meios de que dispõem para melhor atender aos clientes.

\section{EXEMPLO DE UNIDADE DE INFORMAÇÃO QUE UTILIZA SISTEMA DE INTELIGÊN CIA EM SEU S PROCESSOS}

0 exemplo refere-se às atividades do Centro de Q uebec (Canadá) de pesquisa e desenvolvimento do A lumínio (CQRDA ), bem como do Centro de V igilância de $M$ etais Leves ( $C V M L$ ), este último criado para atender às necessidades de organização e disseminação de informação sobre alumínio, dos técnicos do CQRDA.

0 objetivo principal do CVM L é "oferecer produtos e serviços de informação, de consulta e de utilização relacionados aos metais leves e sensibilizar as indústrias acerca do valor da informação estratégica". O s produtos oferecidos pelo CVM L são inúmeros e levam em consideração as diferenças econômicas, tecnológicas, comerciais e de mercado das empresas do Q uebec que atuam com metais leves. São eles: 
- DSI - Disseminação Seletiva da Informação;

- Serviço de referência - respostas às questões pontuais ou que requerem pesquisa;

- Boletins mensais sobre IC;

- Estudo multicliente - estado-da-arte de um mercado ou de uma tecnologia;

- Revisão de literatura e levantamento de novas referências sobre M etais L eves;

- Calendário seletivo de eventos ligados à indústria.

CV M L realizou um mapeamento das necessidades de seus clientes para adequar os produtos oferecidos, procurou, também, assumir uma postura pró-ativa diante das empresas. A organização do CV M L é um bom exemplo de um centro de documentação criado especificamente com o objetivo de servir como apoio a um sistema de monitoramento tecnológico ou inteligência competitiva.

0 primeiro passo na estruturação do Centro foi a busca exaustiva de informações sobre metais leves. A s informações coletadas foram inseridas em base de dados de referência do CV M L. A ssim temos:

- Base de dados comerciais com informações sobre tecnologias, conhecimentos científicos, econômicos e comerciais;

- Informações documentárias de base ( relatórios de pesquisa, periódicos etc.);

- Informação via Internet - com muitas possibilidades, desde catálogos coletivos até grupos que trocam informações (especialistas).

O serviço de referência fica a cargo não só de um bibliotecário, mastambém de um engen heiro que o assiste. A ssim, o trabalho de monitoramento de informações realizado pelo bibliotecário é precedido de levantamento das necessidades de informações dos técnicos. A pós 0 levantamento de informações, estas são repassadas ao engenheiro, que as analisará e as transformará em inteligência, pois o diferencial de informação e inteligência é justamente a análise, portanto indispensável é o papel do analista da informação. Ele, por sua vez, deve ter profundo conhecimento do ambiente interno/externo de sua empresa.
A elaboração do boletim sobre metais leves é bem interessante. O s responsáveis pela sua edição ficam constantemente ligados a tudo que se passa na indústria. A sistemática adotada é a exaustiva busca de informações em todos os tipos de fontes de informação: congressos, feiras, revistas, sites da Internet. Há, depois, uma distribuição de informações em função de sua pertinência, de sua utilidade, de sua novidade e de seu impacto no ambiente estudado. 0 Boletim aborda os seguintes temas: atualidades, informações comerciais, tecnologia e informações sobre corporações. As informações selecionadas são traduzidas (quando for o caso) e encaixadas, após serem sintetizadas, em um dos temas abordados.

O serviço de DSI acontece nos padrões tradicionais adotados por qualquer biblioteca, quando são emitidas listas direcionadas pelo interesse do especialista, com referências bibliográficas. Cabe ao especialista a demanda pela informação que mais Ihe interessa.

Os procedimentos adotados pela experiência relatada podem ser replicadosem qual quer unidade de informação com o foco mais apropriado aos seus objetivos.

A rtigo aceito para publicação em 09.2000

\section{REFERÊNCIAS BIBLIOGRÁFICAS}

A LMEIDA, Fernando C. de; DU MONTIER, Pascal. 0 uso de redes neurais em avaliação de riscos de inadimplência. Revista de Administração, São Paulo, v. 31, n. 1, p. 52-63, jan./mar. 1996.

A RA ÚJO JR., Rogério H enrique de. Estudo de necessidades de informação dos gerentes do setor editorial e gráfico do $D$ istrito F ederal. 178 p. D issertação (M estrado em Ciência da Informação) - D epartamento de Ciência da Informação e D ocumentação, Universidade de Brasília, Brasília, 1998.

BARTER JR, Richard F. In search of excellence in libraires: the management writings of Tom Peters and their implications for library and information services. Library M anagement, v. 15, n. 8, p. 4-15, 1994.

CA ST ELLS, M anuel. A sociedade em rede. Tradução de Roneide $V$ enâncio Majer. Rio de Janeiro : Paz e Terra, 1999.

$\mathrm{CHOO}, \mathrm{Chun} \mathrm{W}$. Information management for the intelligent organization: the art of scanning the environment. 2. ed. [s. I. : A SIS], 1998. (A SIS monograph series).

DA V EN PO RT, Thomas H . E cologia da informação: porque só a tecnologia não basta para o sucesso na era da informação. 2. ed. T radução de Bernadete Siqueira A brão. São Paulo : Futura, 2000.

DA VENPORT, Thomas H.; PRUSAK, Laurence. Conhecimento empresarial: como as organizações gerenciam o seu capital intelectual. Tradução de Lenke Peres. Rio de Janeiro : Campus, 1998.

DEES, J. Gregory. Enterprising nonprofits. $H$ arvard Business Review, v. 76, n. 1, p. 55-67, Jan./Feb. 1998.

GA N DELM A N , H enrique. De G utemberg à Internet: direitos autorais na era digital. Rio de Janeiro : Record, 1997. 


\section{Kira T arapanoff / Rogério H enrique de A raújo Júnior / Patricia M arie Jeanne Cormier}

KOT LER, Philip. A dministração de M arketing: análise, planejamento, implementação e controle. 5. ed. T radução de A ilton Bomfim Brandão. São Paulo : A tlas, 1998.

KOTLER, Philip; ARMSTRONG, Gary. Princípios de marketing. 5. ed. Tradução de A lexandre S. M artins. [s.l.] : Prentice $\mathrm{H}$ al do Brasil, 1993.

MANN, Thomas. Reference service, human nature, copyright and offsite service - in a digital age? Reference \& U ser Services Q uarterly, v. 38, n.1, p.55-61, 1999.

N OKA KA , I.; TA KEU CHI, H . C riação de conhecimento na empresa: como as empresas japonesas geram a dinâmica da inovação. T radução de A na Beatriz Rodrigues e Priscilla M artins C eleste. Rio de Jan eiro : Campus, 1997.

PORTER, M. E. Vantagem competitiva: criando e sustentando um desempenho superior. Tradução de Elizabeth M aria de Pinho Braga. Rio de Janeiro : Campus, 1996.

Q UIN N, J. A .; A NDERSO N, P. ; FILKENSTEIN, S. M aking the most of the best. H arvard Business Review, v.74, n. 2, p. 71-80, M ar./A pr. 1996.

SA PIRO , A rão. Inteligência empresarial: a revolução informacional da ação competitiva. Revista de A dministração de Empresas, São Paulo, v. 33, n. 3, p. 106-124, maio/jun. 1993.
TARAPANOFF, Kira. 0 profissional da informação na sociedade do conhecimento: oportunidades e desafios. In: Seminário Nacional de Bibliotecas U niversitárias, 10., 1998, Fortaleza. [s.l. : s. n.], 1998.

TARAPANOFF, Kira, MIRANDA, Denir Mendes, ARAÚJO JR., Rogério $\mathrm{H}$ enrique de. T écnicas para tomada de decisão nos sistemas de informação. Brasília : Thesaurus, 1995.

TAYLOR, R. S. Value-added process in information systems. Norwood, N.J. : A bley Publishing, 1986.

TJA DEN, Gary S. M easuring the information age business. T echnology A nalysis \& Strategic M anagement, v. 8, n. 3, p. 233-246, 1996.

TURRA, Roberta. Data mining. N otizie dal CIN ECA, n. 24, set. 1998. www.revista.unicamp.br/revista/infotec/informaçao

YOUNG, Peter R. Changing information access economics: new roles for libraries and librarians. Information T echnology and Libraries, p. 103114, Jun. 1994.

ZA NASI, A lessandro. Competitive intelligence trough data mining public sources. Competitive Intelligence R eview, v. 9, n. 1, p. 44-54, 1998. 